\title{
Impact of human disturbance and beliefs on the tree agama Acanthocercus atricollis atricollis in a South African communal settlement
}

\author{
Martin J. Whiting, Kinesh Chetty, Wayne Thine and Pau Carazo
}

\begin{abstract}
We investigated the effects of human disturbance and attitudes on the density of the tree agama Acanthocercus atricollis atricollis in a densely populated rural settlement in South Africa. In this environment agamas live on trees that are harvested for firewood or maintained for fruit production. We conducted visual encounter surveys of A. a. atricollis and interviewed local households to establish whether human attitudes and actions could affect tree agama populations. Although local residents viewed tree agamas negatively ( $50 \%$ of interviewees claimed to have killed an agama) and acted to exclude them from their environment, tree agama density in villages was higher than that of adjacent communal rangelands and than a previously reported density estimate in a nearby protected area. We suggest three major factors that could explain why tree agamas are favoured in this peri-urban landscape in the face of human persecution: firstly, predators such as snakes and raptors are likely to occur at a much lower density in periurban areas; secondly, their primary prey (insects) may be more abundant or accessible in this landscape; thirdly, they may experience less competition for resources.
\end{abstract}

Keywords Acanthocercus atricollis atricollis, habitat degradation, reptile, South Africa, superstitions, tree agama, tree harvesting

\section{Introduction}

T andscape alteration and degradation is an unfortunate $\checkmark$ consequence of a rapidly expanding human population. This pressure on the environment can take two forms: direct harvesting of plants and animals for food or harvesting of key resources on which wildlife may depend (Du Plessis, 1995). In southern African savannahs trees are routinely harvested for firewood and building material,

Martin J. Whiting (Corresponding author) and Kinesh ChetTy School of Animal, Plant and Environmental Sciences, University of the Witwatersrand, Private Bag 3, Wits 2050, South Africa. E-mail martin.whiting@ wits.ac.za

Wayne Twine School of Animal, Plant and Environmental Sciences, University of the Witwatersrand, South Africa, and Wits Rural Facility, Acornhoek, South Africa.

PaU Carazo Laboratorio de Etología, Instituto Cavanilles de Biodiversidad y Biología Evolutiva, Universidad de Valencia, Valencia, Spain.

Received 9 April 2008. Revision requested 25 July 2008.

Accepted 17 September 2008. which is a significant threat to cavity-dwelling vertebrates such as birds and small mammals (Du Plessis, 1995). Certain arboreal lizards such as tree agamas Acanthocercus atricollis atricollis and skinks Trachylepis spp. are not only dependent on trees for refuge (Cooper \& Whiting, 2000; Reaney \& Whiting, 2002) but also use them as foraging vantage points (Vitt et al., 1981). Furthermore, removal of trees influences the thermal environment available to lizards (Vitt et al., 1998), which may have cascading effects in which certain species increase in abundance at the expense of others (Vitt et al., 1998). Consequently, when trees are harvested selectively the landscape is transformed (Germaine \& Wakeling, 2001), and these species may be negatively affected. Therefore, not only are humans competing with wildlife for space but also for key resources.

Smart et al. (2005) recorded higher densities of tree agamas in degraded communal lands compared to a nearby conserved area, noted the presence of tree agamas in rural villages but did not quantify their abundance, and found that local residents had a negative perception of tree agamas and may be persecuting them. The aim of our study was therefore to establish whether tree agamas and humans can coexist in a high-density peri-urban environment and whether human perceptions of tree agamas result in any form of persecution that could affect their viability. A second motivation for focusing on tree agamas is that they are arboreal and therefore dependent on trees, a natural resource used by humans. Consequently, tree agamas may face a dual threat: habitat destruction and persecution by humans.

We surveyed tree agamas in local villages and adjacent disturbed rangelands in the same general area as Smart et al. (2005) for comparison with their measures of tree agama density in a nearby protected area. Because Smart et al. (2005) had established that tree agamas are more densely populated in disturbed areas compared to protected areas we restricted our surveys to a complex of adjoining villages and nearby communal, disturbed rangelands. We addressed anthropomorphic threats to A. a. atricollis by integrating field surveys of tree agamas with questionnaire surveys of local village residents. Our study asked the following questions: (1) Do A. a. atricollis occur in reduced numbers in villages compared to nearby rangelands that are less disturbed? We specifically tested the prediction that tree agamas would occur at lower densities in villages. (2) Are any differences in abundance 
explained by habitat features? (3) What are the traditional beliefs concerning tree agamas and could human attitudes have negative impacts on local populations of $A$. a. atricollis?

\section{Study area and species}

Fieldwork was conducted in seven adjacent villages in Bushbuckridge Local Municipality, Mpumalanga Province (Fig. 1) and adjoining communal rangeland, in an area encompassing $13.3 \mathrm{~km}^{2}$ during September of both 2003 and 2007. Each village was distinct from the next and separated by at least $2-3 \mathrm{~km}$. Bushbuckridge is characterized by high population density, poverty and land-use practices typical of African savannah rangelands such as cattle overstocking and intensive harvesting of firewood (Shackleton, 2000). As such, villages are largely devoid of vegetation except for scattered trees (mainly marula Sclerocarya birrea caffra), hedges and small-scale vegetable gardens. In the late $1990 \mathrm{~s}$ the mean population density was 176 people $\mathrm{km}^{-2}$ (Pollard et al., 1999) and the cattle stocking rate was 0.88 livestock units $\mathrm{ha}^{-1}$ (four times the recommended stocking rate; Parsons et al., 1997). A detailed description of the vegetation, climate and socio-economic conditions of Bushbuckridge is given in Shackleton (2000).

A. a. atricollis occurs from eastern South Africa northwards into Zimbabwe and Mozambique (Branch, 1998). While there has been no recent conservation assessment of this species (IUCN, 2008), it is a wide-ranging (Branch, 1998) and relatively common species (authors, pers. obs.). Tree agamas are large (largest snout-vent length: $167 \mathrm{~mm}$ ), diurnal, arboreal, sexually dichromatic (females are olive coloured with black marbling, and mature males have a bright blue head and throat and a vertebral stripe) and insectivorous (Reaney \& Whiting, 2002). A. a. atricollis is a classic ambush forager that spends most of its time waiting for potential prey on tree trunks or lateral branches (Reaney \& Whiting, 2003).

\section{Methods}

To estimate whether tree agamas are more abundant in villages than in surrounding rangelands we systematically surveyed trees that were sufficiently large to harbour tree agamas (minimum diameter $0.09 \mathrm{~m}$ ) and recorded the

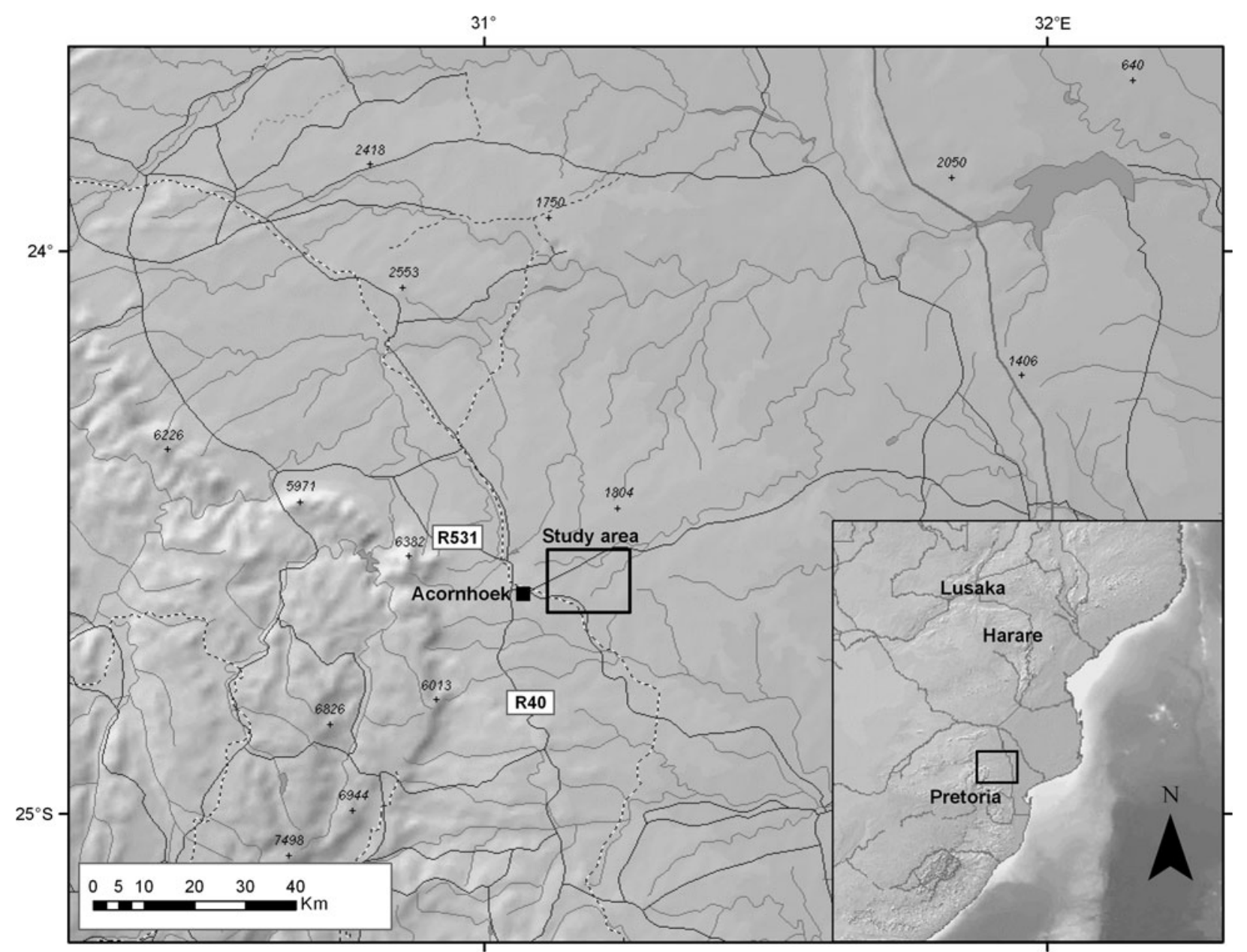

FIG. 1 Location of the study area in the Mpumalanga Province of South Africa. 
number of lizards in each tree. We sampled 300 trees: 150 in the villages and 150 in the adjacent rangelands. Because temporal differences in lizard activity patterns may affect abundance estimates we blocked our sampling procedure so that, within each day, we alternated our sampling site between different habitat types every 10-20 tree surveys. We also balanced each day's starting site (village vs rangeland) so that equal numbers of trees were sampled in both habitat types on the same day, and each habitat type was sampled an equal amount of times within a given time frame across different days (i.e. early morning, mid morning, late morning, midday, early afternoon, late afternoon). Surveys for tree agamas were conducted by two people approaching a tree from opposite sides. We first scanned a tree with binoculars from $>10 \mathrm{~m}$ before slowly approaching. If we recorded a tree agama, we did not survey any trees within a $10 \mathrm{~m}$ radius in case their presence influenced whether a conspecific would occupy a neighbouring tree. We also estimated perch height $(\mathrm{cm})$ and tested for a significant difference between villages and surrounding areas.

We measured the diameter of each tree at breast height (c. $160 \mathrm{~cm}$ ) to the nearest centimetre and estimated tree height to the nearest $1 \mathrm{~m}$. We did not identify tree species but did score whether a tree was a marula because they are maintained for fruit production and dominate the landscape.

We gauged human attitudes and behaviour towards tree agamas through household surveys. Members of a household were asked a series of questions about tree agamas (Table 1). Two pictures of the tree agamas (one of each sex) were shown to the interviewee to ensure correct identification. Three primary themes were covered in the survey: (1) familiarity with A. a. atricollis, (2) beliefs and perceptions about tree agamas, and (3) whether A. a. atricollis and village residents are able to coexist. As previous research in this community established that a negative perception exists towards tree agamas (Smart et al., 2005) we asked the question 'Do tree agamas bring good luck?'. A high

TABLE 1 Survey questionnaire presented to 49 households to gauge their attitudes and beliefs towards tree agamas Acanthocercus atricollis atricollis. Respondents were first presented with pictures of male and female agamas to confirm that they were familiar with the lizard. Question number 3 is a control question (see text for further details).

Do you know this lizard?

Have you seen it often?

Is it true they bring good luck?

Is it true they attract lightning?

What do you know about this lizard?

Do you keep them away from your trees?

If so, how?

Have you ever killed one? proportion of negative responses would suggest that other responses were answered truthfully. The survey was always carried out by KC with the help of a translator fluent in Tsonga. Households were randomly sampled in Sigagula village (Fig. 1), which is relatively central in the study area. We stopped interviewing after 49 households because of the consistent nature of responses.

Because relatively high numbers of trees did not contain A. a. atricollis we used non-parametric Mann-Whitney tests to determine if there was any significant difference in the number of lizards per tree in the villages compared to surrounding rangelands. To examine what factors best predicted lizard abundance (physical characteristics of trees or location) we used general linear modelling. For this we used PROC GENMOD in SAS $v 9.1$ (SAS Institute, Cary, USA) for a Poisson regression model that allows categorical and continuous data. We used stepwise subset selection, in which the criterion for remaining in the model was $\mathrm{P}=0.1$. We then performed a Type 3 analysis to examine the interactive effect of explanatory variables on the main effect. The response variable was number of lizards and the explanatory variables were location and tree height and diameter. All statistical tests are two-tailed.

\section{Results}

We found a significantly $\left(\chi_{1}^{2}=48.95, \mathrm{P}<0.00001\right)$ higher number of tree agamas in villages $(n=97)$ compared to surrounding rangelands $(\mathrm{n}=21$; Fig. 2$)$. The mean number of tree agamas per tree was also significantly higher in villages $(0.65 \pm \mathrm{SE} 0.06)$ than in surrounding rangelands (0.14 \pm SE 0.04; Mann-Whitney $Z=7.4, \mathrm{P}<0.00001)$. Mean perch height was not significantly different $\left(t_{91}=1.77, \mathrm{P}=\right.$ $0.08)$ between villages $(220.4 \pm \mathrm{SE} 16.3 \mathrm{~cm})$ and surrounding rangelands $(287.1 \pm \mathrm{SE} 39.22 \mathrm{~cm})$.

We found no significant differences in the characteristics of trees containing tree agamas between villages and surrounding rangelands: mean diameter (villages: $242.82 \pm \mathrm{SE}$ $7.06 \mathrm{~cm}, \mathrm{n}=79$; rangelands: $258.68 \pm \mathrm{SE} 24.77 \mathrm{~cm}, \mathrm{n}=19$; Mann-Whitney $Z=0.08, \mathrm{P}=0.94$ ) and mean height (villages: $10.27 \pm$ SE $0.25 \mathrm{~m}, \mathrm{n}=79$; rangelands: $9.16 \pm$ SE $0.55 \mathrm{~m}$, $\mathrm{n}=19$; Mann-Whitney $Z=1.74, \mathrm{P}=0.08$ ). There was

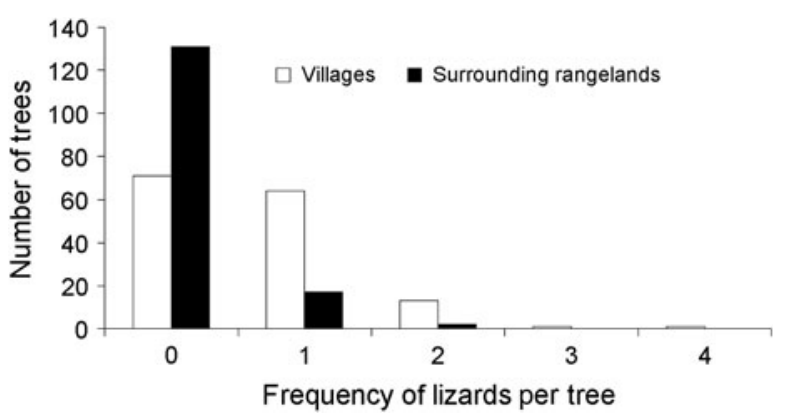

FIG. 2 Frequency of tree agamas encountered on trees in villages and surrounding rangelands. 
a good fit (Pearson $\chi_{297}^{2}=270.5, \mathrm{P}=0.91$ ) for the Poisson regression model describing lizard abundance in relation to location and physical characteristics of trees and the data were not overdispersed, thereby meeting the assumptions of the model. Our final model retained lizard location and tree diameter as explanatory variables for tree agama abundance (Table 2). When interactive effects were examined (Type 3 analysis), location (village vs rangeland) was a more significant predictor of lizard abundance than tree diameter (Table 2).

Seventy-four percent $(n=191)$ of trees sampled $(n=259)$ were marula; $80(31 \%)$ trees contained tree agamas, of which $53(66 \%)$ were marula. Tree agamas used marula trees significantly more $\left(\chi_{1}^{2}=18.2, \mathrm{P}<0.0001\right)$ than all other tree species combined, and this did not depend on location (villages: $\mathrm{n}=31$ of 51 trees, $66 \%$; surrounding areas: $\mathrm{n}=11$ of 23 trees, $48 \%$; Yates' corrected $\chi_{1}^{2}=0.62, \mathrm{P}=0.43$ ).

Of the 49 households interviewed $98 \%$ of respondents recognized the tree agama and all reported seeing them often. The question 'Is it true that tree agamas bring good luck?' was answered positively by only $4 \%$ of interviewees, allowing us to accept the remaining responses with reasonable confidence. Smaller subsets of the population held certain other negative beliefs: $20 \%$ of respondents believed that tree agamas are capable of killing livestock, $18 \%$ that if A. a. atricollis bites a person, the agama will hold on to its victim and will have to be burnt off with hot maize meal, $6 \%$ that the tree agama's brain is poisonous, and $12 \%$ that tree agamas have medicinal properties. As a result of these perceptions of tree agamas a large proportion of respondents $(n=41,84 \%)$ actively excluded tree agamas from trees on their property, either killing them with a stone $(n=7$, $14 \%)$ or by wrapping plastic around the tree trunk $(n=34$, $69 \%)$. Where residents had wrapped plastic around a tree we did not observe any agamas. Almost half $(n=23,47 \%)$ of all respondents reported they had killed tree agamas.

\section{Discussion}

We found the converse of what we had predicted: tree agama density was higher in villages, where human density

TABLE 2 General linear modelling (Poisson regression) of predictors of tree agama abundance. Tree diameter has a marginal effect on tree agama abundance but location is highly significant. Significantly more tree agamas were sighted in villages compared to surrounding rangelands (see text for further details).

\begin{tabular}{lllcc}
\hline Parameter & Estimate & SE & Wald $\chi^{2}$ & $\mathrm{P}$ \\
\hline Location & 1.5228 & 0.2407 & 58.25 & $<0.0001$ \\
Tree diameter & 0.0036 & 0.0014 & 6.82 & 0.009 \\
\cline { 3 - 5 } & & $\mathrm{df}$ & $\chi^{2}$ & $\mathrm{P}$ \\
\cline { 3 - 5 } & & & \\
Type 3 analysis of interactive & effects \\
Location & & 1 & 52.47 & $<0.0001$ \\
Tree diameter & & 1 & 6.40 & 0.0114 \\
\hline
\end{tabular}

is high, than in surrounding communal rangelands. We expected that the more degraded landscape of villages, coupled with a negative human perception of tree agamas, would have an additive effect that would reduce lizard density. This paradox may be resolved by several explanations that need not be mutually exclusive. The primary factors likely to promote tree agama population growth are food availability, the suppression of competition and the removal of natural predators. A less likely explanation is that fire may have a greater effect on agamas in rangelands than in villages, either directly or indirectly through reduction of food availability. However, rangelands that surround villages are typically overgrazed and have relatively low fuel loads (Smart et al., 2005), suggesting that fire is unlikely to significantly affect agama populations.

Tree agamas eat large numbers of ants and beetles, although grasshoppers comprise a high proportion of their diet by volume (Reaney \& Whiting, 2002). Grass and vegetation in general are limited in villages, which comprise mostly bare ground. Therefore, although we did not measure insect prey availability, it is unlikely that grasshoppers and ants would be more abundant in villages, given that both groups are likely to experience low food availability. Alternatively, other factors may have promoted insect availability, or agamas may have switched to eating insects that are more readily available in villages.

The removal of natural predators can cause an increase in the abundance of prey species (Case et al., 1998). Snakes, a known predator of $A$. a. atricollis (authors, pers. obs.), are generally killed on sight in villages (Smart et al., 2005). Other potential predators include feral domestic cats and raptors, both of which are less common in villages (Lewis, 1997). Therefore, tree agamas are probably experiencing lower natural predation pressure in villages than in the surrounding rangelands.

Based on the interviews we conclude that village tree agamas face the additional threat of human persecution. However, we did not quantify the frequency with which residents kill tree agamas, so it is possible that killing by humans is relatively insignificant and therefore insufficient to offset natural predation levels.

Many factors drive the community ecology of savannah ecosystems but chief among those that affect the plant community are the actions of herbivores (Owen-Smith, 1988). In undisturbed African savannahs with typical browsing pressure marula trees probably occurred at low densities (Cunningham \& Shackleton, 2004). However, given that marula fruit has been a key resource for at least the past 2,000 years of agriculture in southern African savannahs it is likely that human action has increased their abundance (Cunningham \& Shackleton, 2004). In particular, disturbed areas not only have fewer browsers because of anthropogenic disturbance but many trees are protected from browsing by fencing. 
Tree agamas have been reported to select trees of a particular species and physical complexity (Reaney \& Whiting, 2003). At our study site the landscape has been radically altered by years of selective tree harvesting, resulting in a tree community with low diversity. In particular, marula trees are among the more common large trees. Marula are large enough and sufficiently complex structurally to be readily used by tree agamas, so the availability of marula trees may be a key factor contributing to their resilience in rural settlements. If levels of tree harvesting for fuelwood in communal areas increase, tree agamas may in future become more restricted to human settlements, where they could use trees that are grown specifically for economic purposes. The future of tree agamas in rural communities therefore appears to be linked to the economic benefits afforded from growing marula trees in homesteads. Paradoxically, tree agamas represent an example of a native species that has benefited from historical human action and is currently relatively abundant despite the best efforts of humans to exclude them from their domain. Although tree agamas appear to be secure and occur in relatively high abundance in a modified landscape, we need a better understanding of how degraded ecosystems function and whether altering the abundance of top level predators may increase the potential for detrimental cascading effects on other, less conspicuous groups, such as invertebrates.

\section{Acknowledgements}

This study was funded by grants to MJW from the National Research Foundation of South Africa and the University of the Witwatersrand. WT was funded by the National Lottery Distribution Trust Fund. For field assistance we thank Skusi Nardini, Solly B. Zitha and Themba H. Ngobeni. We also greatly appreciate the support and cooperation of the Timbavati community.

\section{References}

Branch, B. (1998) A Field Guide to Snakes and Other Reptiles of Southern Africa. Struik Publishers, Cape Town, South Africa.

Case, T.J., Bolger, D.T. \& Richman, A.D. (1998) Reptilian extinctions over the last ten thousand years. In Conservation Biology for the Coming Decade (eds P.L. Fiedler \& P.M. Kareiva), pp. 91-125. Chapman \& Hall, New York, USA.

Cooper, W.E. \& Whiting, M.J. (2000) Islands in a sea of sand: use of Acacia trees by tree skinks in the Kalahari Desert. Journal of Arid Environments, 44, 373-381.

Cunningham, A.B. \& Shackleton, C.M. (2004) Use of fruits and seeds from indigenous and naturalised plant species. In Indigenous Forests and Woodlands in South Africa (eds M.J. Lawes, H.A.C. Eeley, C.M. Shackleton \& B.G.S. Geach), pp. 603-617. University of KwaZulu-Natal Press, Scottsville, USA.

Du Plessis, M.A. (1995) The effects of fuelwood removal on the diversity of some cavity-using birds and mammals in South Africa. Biological Conservation, 74, 77-82.
Germaine, S.S. \& WAKeling, B.F. (2001) Lizard species distributions and habitat occupation along an urban gradient in Tucson, Arizona, USA. Biological Conservation, 97, 229-237.

IUCN (2008) 2008 IUCN Red List of Threatened Species. IUCN, Gland, Switzerland. Http://www.iucnredlist.org [accessed 12 June 2009].

LEWIS, S.N. (1997) Birds as indicators of biodiversity: a study of avifaunal diversity and composition in two contrasting land-use types in the Eastern Transvaal lowveld, South Africa. MSc thesis, University of East Anglia, Norwich, UK.

OWen-Smith, R.N. (1988) Megaherbivores: The Influence of Very Large Body Size on Ecology. Cambridge University Press, Cambridge, UK.

Parsons, D.A.B., Shackleton, C.M. \& Scholes, R.J. (1997) Changes in herbaceous layer condition under contrasting land-use systems in the semi-arid lowveld, South Africa. Journal of Arid Environments, 37, 319-329.

Pollard, S.R., Perez de Meniguren, J.C., Joubert, A., Shackleton, C.M., Walker, P., Poulter, T. \& White, M. (1999) Save the Sand. Phase 1. Feasibility Study: The Development of a Proposal for the Catchment Plan for the Sand River. Unpublished Report submitted to the national Department of Water Affairs and Forestry, Pretoria, South Africa.

ReAney, L.T. \& Whiting, M.J. (2002) Life on a limb: ecology of the tree agama (Acanthocercus a. atricollis) in southern Africa. Journal of Zoology (London), 257, 439-448.

Reaney, L.T. \& Whiting, M.J. (2003) Picking a tree: habitat use by the tree agama, Acanthocercus atricollis atricollis, in South Africa. African Zoology, 38, 273-278.

SHACKLETON, C.M. (2000) Comparison of plant diversity in protected and communal lands in the Bushbuckridge lowveld savanna, South Africa. Biological Conservation, 94, 273-285.

Smart, R.M., Whiting, M.J. \& Twine, W. (2005) Lizards and landscapes: integrating field surveys and interviews to assess the impact of human disturbance on lizard assemblages and selected reptiles in a savanna in South Africa. Biological Conservation, $122,23-31$.

Vitt, L.J., Avila-Pires, T.C.S., Caldwell, J.P. \& Oliveira, V.R.L. (1998) The impact of individual tree harvesting on thermal environments of lizards in Amazonian rain forest. Conservation Biology, 12, 654-664.

Vitt, L.J., van Loben Sels, R.C. \& Ohmart, R.D. (1981) Ecological relationships among arboreal desert lizards. Ecology, 62, 398-410.

\section{Biographical sketches}

MARTIN WHITING's primary research interests span behavioural and evolutionary ecology, including conservation biology. He works primarily with reptiles, and lizards in particular. The majority of his field work has been in southern Africa, although he has also worked on species of conservation concern in North America and Australia. Kinesh Chetty is involved in the implementation of Clean Development Mechanism projects in sub-Saharan Africa aimed at promoting the development of clean energy technologies in developing countries. WAYNE TWINE manages a research programme focusing on human-environment interactions in rural commonproperty resource systems. PAU CARAZO's principal area of research is behavioural ecology. He has conducted research on social communication in lacertid lizards and on sperm competition and sexual conflict in beetles. 